\title{
INTERPRETASI PRAKTIS TERHADAP ISTILAH-ISTILAH DAYA PADA RANGKAIAN LISTRIK SATU FASE SINUSOIDAL
}

\author{
Adlan Bagus Pradana ${ }^{1}$, Unan Yusmaniar Oktiawati ${ }^{2}$, Jimmy Trio Putra ${ }^{3}$, Dhanis Woro Fittrin Selo Nur \\ Giyatno $^{4}$, Atikah Surriani ${ }^{5}$ \\ 1,2,3,4,5 Dept. Teknik Elektro dan Informatika, Sekolah Vokasi, Universitas Gadjah Mada \\ adlan.pradana@ugm.ac.id ${ }^{1}$,unan_yusmaniar@ugm.ac.id ${ }^{2}$,jimmytrioputra@ugm.ac.id ${ }^{3}$, \\ dhanisworo@ugm.ac.id ${ }^{4}$, atikah.surriani.sie13@mail.ugm.ac.id ${ }^{5}$
}

\begin{abstract}
In electrical engineering, there are several power terms; active power, reactive power, instantaneous active power, instantaneous active power, instantaneous power, apparent power and complex power. Even though are used in daily activity, electrical practitioners are facing difficulty to explain those terms practically. This paper tries to solve those difficulties by interpret those term in practical way. Firstly, each power term is defined theoretically. Then those terms are presented mathematically. Next, power in single phase sinusoidal electric network is analyzed. Theoretical definition result is connected with power analysis result. Computer simulations are held to strengthen interpretation result. Considering the width of discussion area, this paper only covers most general application, that is single phase sinusoidal network.

Keywords : practical interpretation, analysis, power terms, electrical network, single phase sinusoidal.

Intisari - Dalam dunia teknik elektro, dikenal istilah-istilah daya, yaitu daya aktif, daya reaktif, daya aktif sesaat, daya reaktif sesaat, daya sesaat, daya semu dan daya kompleks. Walaupun lazim digunakan sehari-hari, para praktisi teknik elektro kerapkali kesulitan untuk menjelaskan secara praktis pengertian dari masing-masing istilah tersebut. Tulisan ini mencoba mengatasi kesulitan tersebut dengan menginterpretasikan secara praktis istilah-istilah daya tersebut. Interpretasi diawali dengan melakukan definisi dari istilah-istilah daya tersebut. Kemudian dilakukan penjabaran secara teoritis melalui persamaan matematis. Langkah berikutnya adalah melakukan analisis daya pada rangkaian listrik satu fase sinusoidal. Hasil penjabaran teoritis dihubungkan dengan hasil analisis daya. Simulasi dengan komputer juga dilakukan untuk memperkuat interpretasi praktis. Mengingat luasnya cakupan, diskusi akan dibatasi untuk penerapan yang paling umum, yaitu pada rangkaian listrik satu fase sinusoidal.
\end{abstract}

Kata kunci : interpretasi praktis, analisis, istilah daya, rangkaian listrik, satu fase sinusoidal.

\section{PENDAHULUAN}

Istilah-istilah daya yaitu daya aktif, daya reaktif daya aktif sesaat, daya reaktif sesaat, daya sesaat, daya semu dan daya kompleks, telah didiskusikan oleh beberapa ahli sejak lama. Knowlton [1] melakukan klarifikasi terhadap konsep daya reaktif, dilanjutkan oleh Smith [2] dan Johnson yang [3] mendiskusikan konsep daya reaktif dari sudut pandang teori dan praktis. Curtis dan Sislbee [4] mendefinisikan daya sesaat, daya aktif, daya semu, daya reaktif, lalu mengembangkan konsepnya untuk aplikasi satu fase sinusoidal, satu fase non-sinusoidal, polifase seimbang sinusoidal, polifase seimbang non-sinusoidal, polifase tak seimbang sinusoidal, dan polifase tak seimbang non-sinusoidal. Akagi dan kawan-kawan []] dalam usahanya untuk merancang kompensator daya reaktif, mengusulkan konsep baru bernama daya imajiner sesaat dan daya reaktif sesaat. Czarnecki [6] mendiskusikan beberapa misinterpretasi terhadap daya semu dan daya sesaat. Emmanuel [7] mendiskusikan dan menginterpretasikan daya semu beserta semua komponennya. Czarnecki [8] mendiskusikan beberapa pertanyaan yang muncul terkait daya listrik. IEEE [9] menerbitkan versi uji coba dari standar definisi pengukuran besaran daya listrik untuk kondisi sinusoidal, non-sinusoidal, seimbang dan tak seimbang. Standar ini kemudian diperbarui pada tahun 2010 [10]. Willems [11] membandingkan standar IEEE 1459-2010 dengan standar dari DIN 40110.

Walaupun telah banyak dibahas sebelumnya, diskusi dan interpretasi praktis perihal istilah-istilah daya ini masih dipandang perlu. Tujuannya adalah agar istilah-istilah daya ini menjadi lebih mudah dimengerti. Sebagai penyederhanaan, lingkup diskusi dibatasi pada kasus yang paling umum, yaitu pada sistem satu fase sinusoidal. Semua definisi pada diskusi ini disandarkan pada standar [10], kecuali dinyatakan berbeda.

\section{METODE PENELITIAN}

Metode yang dipakai pada tulisan ini pertama-tama adalah dengan melakukan definisi dari istilah-istilah daya tersebut. Kemudian dilakukan penjabaran secara teoritis melalui persamaan matematis. Langkah berikutnya adalah melakukan analisis daya pada rangkaian listrik satu fase sinusoidal. Hasil penjabaran teoritis dihubungkan dengan hasil analisis daya. Simulasi dengan komputer juga dilakukan untuk memperkuat interpretasi praktis.

\section{A. Penjabaran Teoritis}

Pada sistem satu fase sinusoidal, tegangan sesaat $(v)$ didefinisikan sebagai,

$$
v=\sqrt{2} V \sin \omega t
$$

dimana,

$V=$ nilai rms tegangan $(V)$

$\omega=$ kecepatan sudut $(\mathrm{rad} /$ detik $)$

$t=$ waktu $($ detik)

Pada sistem satu fase sinusoidal, sumber tegangan sesaat sinusoidal juga akan menghasilkan arus sesaat (i) 
sinusoidal, dengan fase sebesar $\theta$ (diasumsikan tertinggal),

$$
i=\sqrt{2} I \sin (\omega t-\theta)
$$

dimana,

$I=$ nilai $r m s$ arus $(A)$

$\theta=$ sudut terhadap tegangan (radian)

Daya sesaat $(p)$ adalah hasil kali tegangan sesaat $(v)$ dan arus sesaat $(i)$,

dimana,

$$
p=v i
$$

$p=$ daya sesaat $(W)$

$v=$ tegangan sesaat $(V)$

$i=\operatorname{arus}$ sesaat $(A)$

Arus dapat diurai menjadi komponen sefase tegangan $\left(i_{a}\right)$ dan komponen tegak lurus tegangan $\left(i_{q}\right) . i_{a}$ didefinisikan sebagai komponen aktif arus, dan $i_{q}$ didefinisikan sebagai komponen reaktif arus.

$$
\begin{gathered}
i=i_{a}+i_{q} \\
i=\sqrt{2} I(\sin \omega t \cos \theta-\sin \theta \cos \omega t) \\
i=\sqrt{2} I\left[\sin \omega t \cos \theta-\sin \left(\frac{\pi}{4}-\omega t\right) \sin \theta\right] \\
i_{a}=\sqrt{2} I \sin \omega t \cos \theta \\
i_{q}=-\sqrt{2} I \sin \theta \cos \omega t \\
i_{q}=-\sqrt{2} I \sin \left(\frac{\pi}{4}-\omega t\right) \sin \theta
\end{gathered}
$$

dimana,

$i_{a}=$ komponen aktif arus $(A)$

$i_{q}=$ komponen reaktif arus $(A)$

Karena arus memiliki 2 komponen, maka daya yang merupakan hasil kali tegangan dan arus juga memiliki 2 komponen, yaitu daya aktif sesaat $\left(p_{a}\right)$ dan daya reaktif sesaat $\left(p_{q}\right)$. Daya aktif sesaat $\left(p_{a}\right)$ didefinisikan sebagai hasil kali tegangan $(v)$ dengan komponen aktif arus $\left(i_{a}\right)$, dan daya reaktif sesaat $\left(p_{q}\right)$ didefinisikan sebagai hasil kali tegangan $(v)$ dengan komponen reaktif arus $\left(i_{q}\right)$.

$$
\begin{gathered}
p=p_{a}+p_{q} \\
p=v i_{a}+v i_{q} \\
p=\sqrt{2} V \sin \omega t \cdot \sqrt{2} I \sin \omega t \cos \theta-\sqrt{2} V \sin \omega t \\
p=2 V I \cos \theta \sin ^{2} \omega t-2 V I \sin \\
\text { dimana, } \\
p_{a}=\text { daya aktif sesaat }(W) \\
p_{q}=\text { daya reaktif sesaat }(W)
\end{gathered}
$$$$
p=\sqrt{2} V \sin \omega t \cdot \sqrt{2} I \sin \omega t \cos \theta-\sqrt{2} V \sin \omega t .(-\sqrt{2} I \sin \theta \cos \omega t)
$$$$
p=2 V I \cos \theta \sin ^{2} \omega t-2 V I \sin \theta \sin \omega t \cos \omega t
$$

Dengan menggunakan identitas trigonometri $\left(\sin ^{2} A=\right.$ $1-\cos 2 A$, dan $2 \sin A \cos A=\sin 2 A$ ), didapatkan,

$$
p=V I \cos \theta(1-\cos 2 \omega t)-V I \sin \theta \sin 2 \omega t
$$

Sehingga,

$$
\begin{gathered}
p_{a}=V I \cos \theta(1-\cos 2 \omega t) \\
p_{q}=-V I \sin \theta \sin 2 \omega t
\end{gathered}
$$

Daya aktif $(P)$ didefinisikan sebagai rerata daya aktif sesaat $\left(p_{a}\right)$ selama 1 siklus. Jika diperhatikan daya aktif sesaat $\left(p_{a}\right)$ memiliki 2 komponen, yaitu komponen konstan $V I \cos \theta$ dan komponen sinusoidal $V I \cos \theta \cos 2 \omega t$.

$$
\begin{gathered}
p_{a}=p_{a 0}+p_{a 1} \\
p_{a 0}=V I \cos \theta \\
p_{a 1}=-V I \cos \theta \cos 2 \omega t
\end{gathered}
$$

dimana,

$p_{a 0}=$ komponen konstan $p_{a}(W)$

$p_{a 1}=$ komponen sinus $p_{a}(W)$

Rerata 1 siklus dari suatu konstanta adalah konstanta itu sendiri, sedangkan karena merupakan fungsi sinusoidal, rerata fungsi $\left(\overline{p_{a 1}}\right)$ selama 1 siklus adalah nol, sehingga rerata daya aktif sesaat $\left(\overline{p_{a}}\right)$ selama 1 siklus adalah $V I \cos \theta$.

$$
\begin{gathered}
P=\overline{p_{a}} \\
P=\overline{p_{a 0}}+\overline{p_{a 1}} \\
\overline{p_{a 0}}=V I \cos \theta \\
\overline{p_{a 1}}=0 \\
P=V I \cos \theta
\end{gathered}
$$

dimana,

$\overline{p_{a 0}}=$ rerata $p_{a 0}$ selama satu siklus $(W)$

$\overline{p_{a 1}}=$ rerata $p_{a 1}$ selama satu siklus $(W)$

Daya reaktif $(Q)$ didefinisikan sebagai nilai amplitudo daya reaktif sesaat $\left(p_{q}\right)$, sehingga,

dimana,

$$
\begin{gathered}
Q=\left|p_{q}\right| \\
Q=V I \sin \theta
\end{gathered}
$$

$\left|p_{q}\right|=$ amplitudo daya reaktif sesaat (VAR)

$Q=$ daya aktif (VAR)

Daya semu $(S)$ didefinisikan sebagai hasil kali root mean square (rms) tegangan dan arus,

$$
S=V I
$$

dimana,

$S=$ daya semu $(V A)$

Daya kompleks $(\boldsymbol{S})$ didefinisikan sebagai besaran kompleks dimana komponen riilnya adalah daya aktif $(P)$ dan kompenen imajinernya adalah daya reaktif $(Q)$,

$$
\boldsymbol{S}=P+j Q
$$

\section{B. Analisis Daya pada Rangkaian Listrik}

Dimisalkan suatu rangkaian listrik satu fase, dengan sumber tegangan sinusoidal $(v)$, dan suatu beban linear. Beban linear ini akan menyebabkan arus yang sinusoidal pula $(i)$, dengan fase sebesar $(\theta)$ terhadap tegangan (diasumsikan mendahului). Daya sesaat yang mengalir di rangkaian tersebut pada saat $(t)$ adalah (3). Dengan menggunakan prinsip superposisi, daya dapat diurai paralel menjadi daya resistif $\left(p_{r}\right)$, dan daya non-resistif $\left(p_{n r}\right)$. Karena beban diurai menjadi dua, maka arus yang mengalir melalui beban juga dapat diurai menjadi dua, yaitu arus resistif $\left(i_{r}\right)$ yang mengalir melalui beban resistif $\left(p_{r}\right)$, dan arus non-resistif $\left(i_{n}\right)$ yang mengalir melalui beban non-resistif $\left(p_{n}\right)$. Karena bersifat resistif, arus resistif $\left(i_{r}\right)$, selalu sefase dengan tegangan. Sebaliknya, karena non-resistif, dan mendahului, arus non-resistif $\left(i_{n}\right)$ pastilah kapasitif yang mana fasenya tegak lurus terhadap tegangan. 


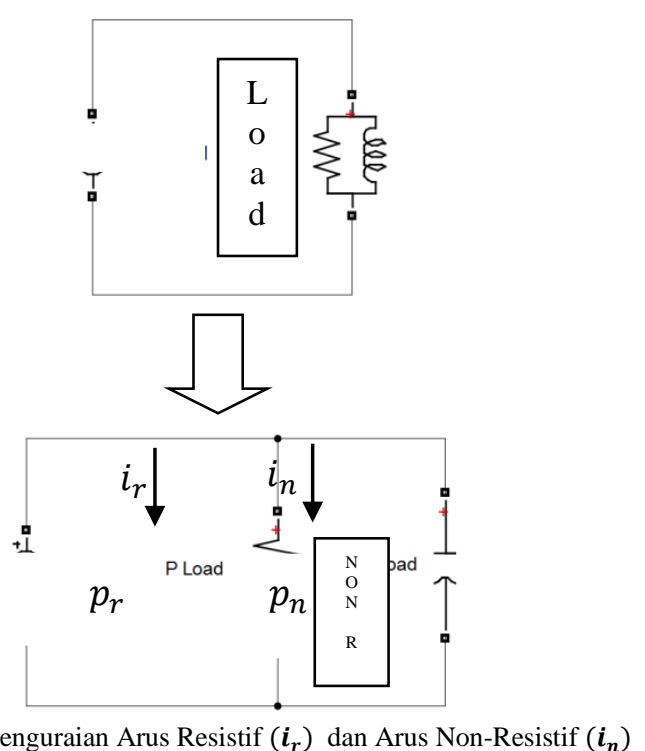

\section{HASIL DAN PEMBAHASAN}

\section{A. Interpretasi Praktis}

Dari penjabaran teoritis dan analisis daya, saat beban diurai secara paralel, secara praktis dapat diinterpretasikan bahwa,

$$
\begin{gathered}
i_{a}=i_{r} \\
i_{q}=i_{n r} \\
p_{a}=p_{r} \\
p_{q}=p_{n r}
\end{gathered}
$$

dimana,

$i_{r}=\operatorname{arus}$ resistif $(A)$

$i_{n r}=\operatorname{arus}$ non - resistif $(A)$

Lebih lanjut lagi, dengan menerapkan identitas trigonometri pada (14), didapatkan,

$$
\begin{gathered}
p=V I \cos \theta-V I(\cos \theta \cos 2 \omega t+\sin \theta \sin 2 \omega t) \\
p=V I \cos \theta-V I \cos (\theta-2 \omega t)
\end{gathered}
$$

Persamaan (34) memiliki 2 komponen, yaitu komponen konstan $\left(p_{0}\right)$, dan komponen sinusoidal $\left(p_{1}\right)$.

$$
\begin{gathered}
p=p_{0}+p_{1} \\
p_{0}=V I \cos \theta \\
p_{1}=-V I \cos (\theta-2 \omega t)
\end{gathered}
$$

dimana,

$$
\begin{aligned}
& p_{0}=\text { komponen konstan } p(W) \\
& p_{1}=\text { komponen sinusoidal } p(W)
\end{aligned}
$$

Dari (35)-(37), secara matematis dapat diinterpretasikan bahwa daya aktif $(P)$ adalah rerata daya sesaat dalam 1 siklus $(\bar{p})$.

$$
P=\bar{p}
$$

dimana,

$$
\bar{p}=\operatorname{rerata} p(W)
$$

Walau (38) berbeda dengan (20), namun hal ini tidaklah mengherankan. Dengan menggunakan prinsip superposisi, rerata daya sesaat dalam 1 siklus $(\bar{p})$ adalah penjumlahan rerata daya aktif dalam 1 siklus $\left(\overline{p_{a}}\right)$ dan rerata daya reaktif dalam 1 siklus $\left(\overline{p_{q}}\right)$. Sedangkan dalam 1 siklus $\overline{p_{q}}$ bernilai nol. Sehingga, dimana,

$$
\begin{gathered}
\bar{p}=\overline{p_{a}}+\overline{p_{q}} \\
\overline{p_{q}}=0 \\
\bar{p}=p_{a}
\end{gathered}
$$

$\overline{p_{q}}=\operatorname{rerata} p_{q}(W)$

\section{B. Simulasi Komputer}

Simulasi dilakukan dengan bantuan program Simulink/MATLAB sebagaimana diilustrasikan pada gambar 2. Sesuai analisis daya, dilakukan simulasi dengan sumber tegangan sinusoidal dan beban linear. Simulasi dilakukan sebanyak $2 \mathrm{kali}$, yaitu (1) beban resistif dan beban induktif dengan faktor daya total 0,8 , (2) beban resistif dan beban kapasitif dengan faktor daya 0,5. Lalu dipasang scope untuk melihat nilai dari setiap daya. Setiap scope memiliki 2 input, yaitu nilai teoritis matematis dan nilai interpretasi praktis agar dapat dibandingkan secara langsung. Scope untuk daya sesaat $[p(t)]$, daya semu $(S)$, daya aktif $(P)$ dan daya reaktif $(Q)$ diletakkan di percabangan utama. Sedang scope untuk daya aktif sesaat $\left[p_{a}(t)\right]$ dan daya reaktif sesaat $\left[\left(p_{q}(t)\right]\right.$ diletakkan di masing-masing cabang.

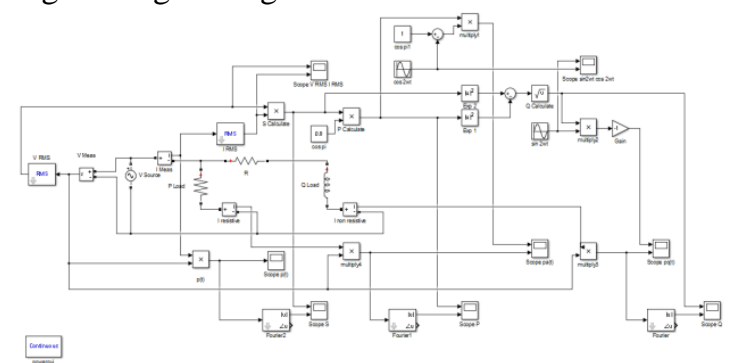

Gambar 2. Diagram Simulink/MATLAB

1. Daya Aktif Sesaat

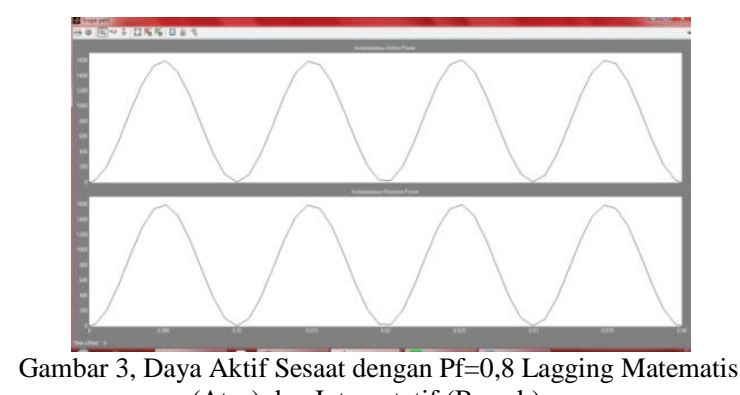
(Atas) dan Intepretatif (Bawah)

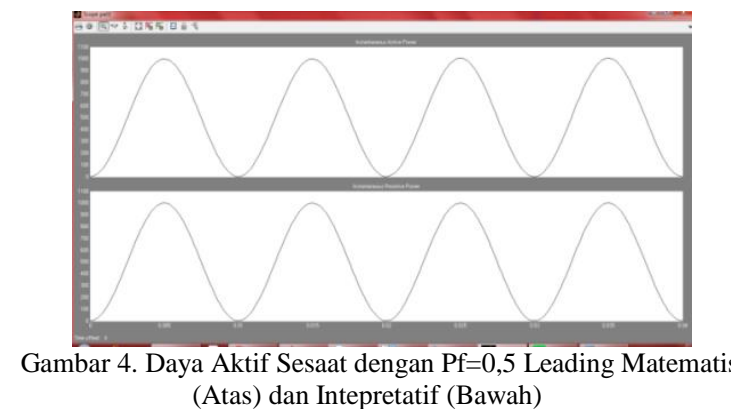

Dari gambar 3 dan gambar 4, dapat dilihat bahwa grafik daya aktif sesaat secara matematis sama persis dengan daya aktif sesaat secara intepretatif baik pada $\mathrm{pf}=0,8$ lagging, maupun pada $\mathrm{p}=0,5$ leading. 
2. Daya Reaktif Sesaat

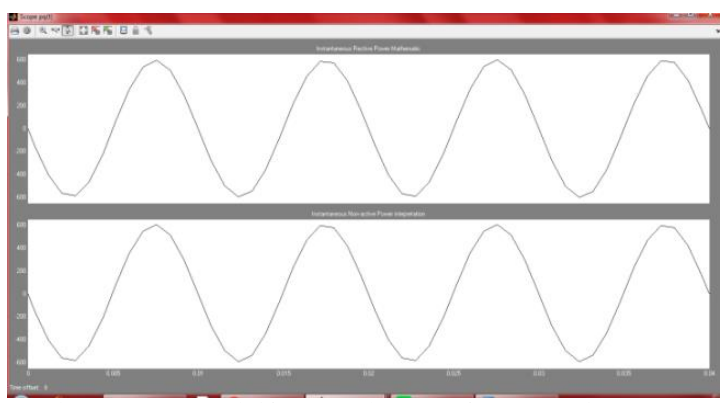

Gambar 5. Daya Reaktif Sesaat dengan $\mathrm{Pf}=0,8$ Lagging Matematis (Atas) dan Intepretatif (Bawah)

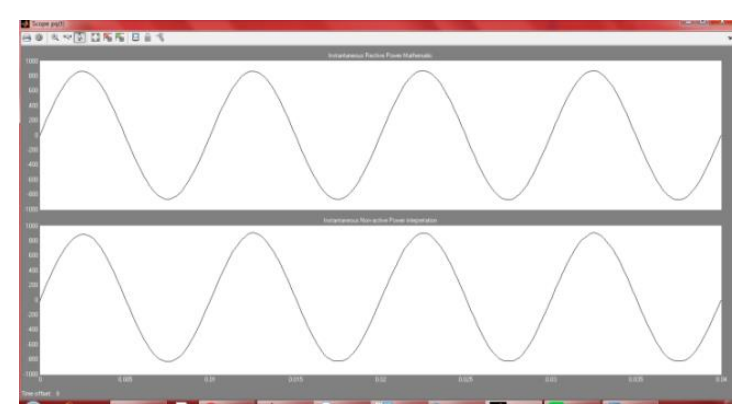

Gambar 6. Daya Reaktif Sesaat dengan $\mathrm{Pf}=0,5$ Leading Matematis (Atas) dan Intepretatif (Bawah)

Dari gambar 5 dan gambar 6, dapat dilihat bahwa grafik daya reaktif sesaat secara matematis sama persis dengan daya reaktif sesaat secara intepretatif baik pada $\mathrm{pf}=0,8$ lagging, maupun pada $\mathrm{pf}=0,5$ leading.

\section{Daya Semu}

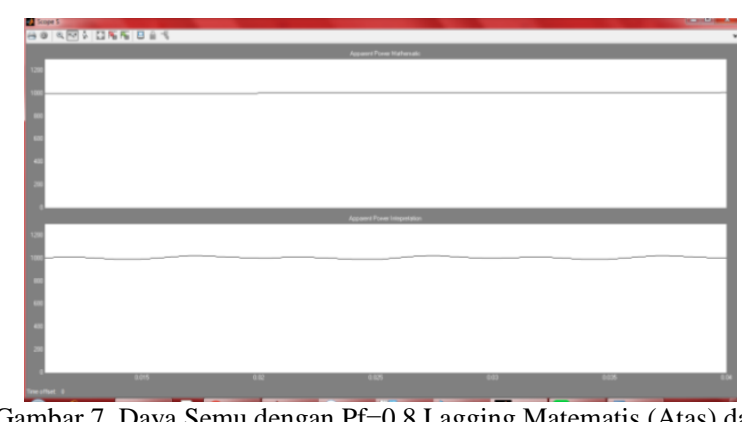
Intepretatif (Bawah)

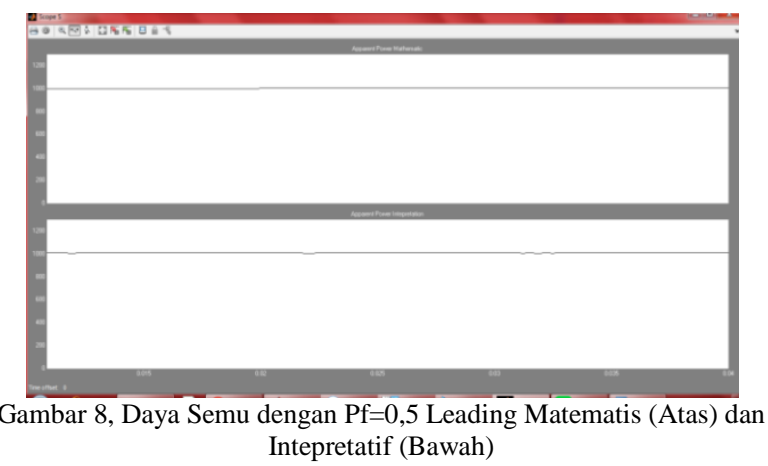

Dari gambar 7 dan gambar 8, dapat dilihat bahwa grafik daya semu secara matematis sama persis dengan daya semu secara intepretatif baik pada $\mathrm{pf}=0,8$ lagging, maupun pada $\mathrm{pf}=0,5$ leading.

\section{Daya Aktif}

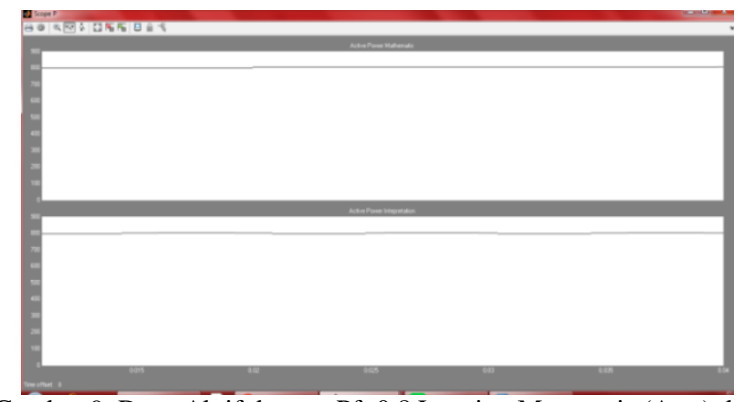

Gambar 9, Daya Aktif dengan Pf=0,8 Lagging Matematis (Atas) dan Intepretatif (Bawah)

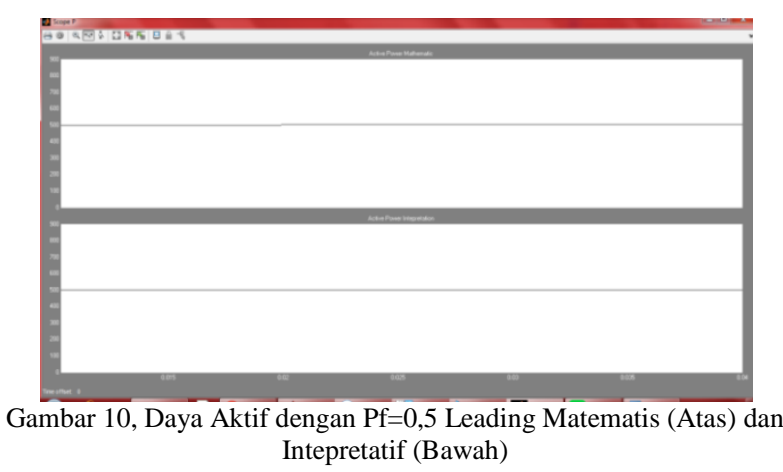

Dari gambar 9 dan gambar 10, dapat dilihat bahwa grafik daya aktif secara matematis sama persis dengan daya aktif secara intepretatif baik pada $\mathrm{pf}=0,8$ lagging, maupun pada $\mathrm{p}=0,5$ leading.

\section{Daya Reaktif}

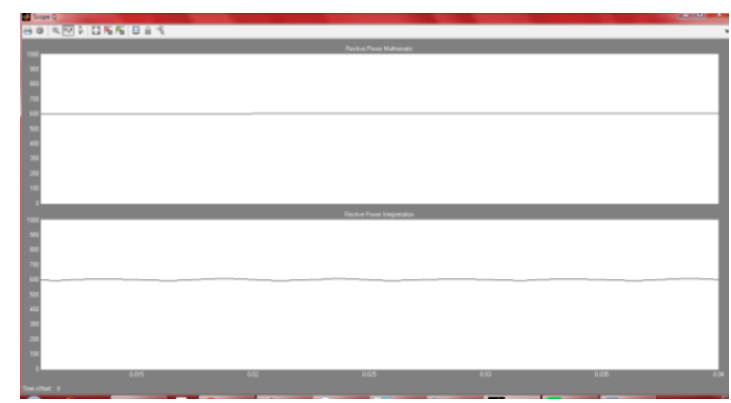

Gambar 11 Daya Reaktif dengan $\mathrm{Pf}=0,8$ Lagging Matematis (Atas) dan Intepretatif (Bawah)

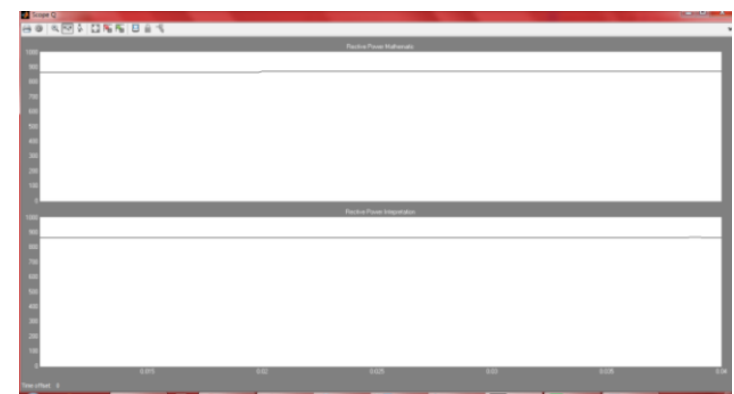

Gambar 12, Daya Semu dengan Pf=0,5 Leading Matematis (Atas) dan Intepretatif (Bawah)

Dari gambar 9 dan gambar 10, dapat dilihat bahwa grafik daya reaktif secara matematis sama persis dengan daya reaktif secara intepretatif baik pada $\mathrm{pf}=0,8$ lagging, maupun pada $\mathrm{p}=0,5$ leading . 


\section{KESIMPULAN}

Istilah-istilah daya seperti yang terdapat pada [10] telah didiskusikan dan dijabarkan secara matematis untuk sistem satu fase sinusoidal. Telah dilakukan pula analisis daya pada rangkaian listrik satu fase sinusoidal. Kemudian masing-masing istilah daya diinterpretasikan secara praktis dengan peristiwa yang terjadi pada rangkaian listrik. Hasil penghubungan ini diverifikasi dengan simulasi program komputer.

Dari proses ini disimpulkan bahwa pada rangkaian listrik satu fase sinusoidal, daya yang mengalir tidak konstan, melainkan berubah-ubah. Secara intepretatif praktis, ini adalah daya sesaat $(p)$. Daya sesaat memiliki 2 komponen, yaitu konstan dan sinusoidal. Komponen sinusoidal daya sesaat memiliki amplitudo. Secara intepretatif praktis, nilai amplitudo komponen sinusoidal daya sesaat ini adalah daya semu $(S)$, sedangkan komponen konstannya adalah daya aktif $(P)$.

Selanjutnya jika beban diurai paralel menjadi beban resistif dan non resistif, secara intepretatif praktis daya yang mengalir ke beban resistif, adalah daya aktif sesaat $p_{a}(t)$, sedangkan daya yang mengalir ke beban nonresisitif, adalah daya reaktif sesaat $\left(p_{q}\right)$. Daya aktif sesaat memiliki komponen konstan dan komponen sinusoidal. Komponen konstan daya aktif sesaat ini dapat pula diinterpretasikan secara praktis sebagai daya aktif $(P)$. Daya reaktif sesaat berbentuk sinusoidal, dan memiliki amplitudo. Secara intepretatif praktis, amplitudo daya reaktif sesaat ini adalah daya reaktif $(Q)$. Dapat dibuat suatu besaran kompleks dengan nilai riil $P$ dan nilai imajiner $(Q)$, besaran ini disebut daya kompleks $(\boldsymbol{S})$.

Interpretasi fisis ini hanya valid untuk sistem satu fase sinusoidal. Namun tidak menutup kemungkinan interpretasi ini juga valid untuk sistem yang lebih umum. Pembuktiannya masih membutuhkan usaha lebih lanjut.

\section{DAFTAR PUSTAKA}

[1] ARCHER E. KNOWLTON, "Reactive Power Concepts," Transactions of the American Institute of Electrical Engineers, vol. 52, no. 3, pp. 744-747, September 1933.

[2] V. G. SMITH, "Reactive and Fictitious Power," Transactions of the American Institute of Electrical Engineers, vol. 52, no. 3, p. 1933, September 1933.

[3] ALLEN JOHNSON, "Operating Aspects of Reactive Power," Transactions of the American Institute of Electrical Engineers, vol. 52, no. 3, pp. 752-757, September 1933.

[4] H. L. Curtis and F. B. Silsbee, "Definitions of power and related quantities," Electrical Engineering, vol. 54, no. 10, pp. 1120-1121, October 1935.

[5] Yoshihira Kanazawa, Koetsu Fujita, Akira Nabae Hirofumi Akagi, "Generalized theory of instantaneous reactive power and its application," Electrical Engineering in Japan, vol. 103, no. 4, pp. 483-490, July 1983.

[6] L.S. Czarnecki, "Misinterpretations of some power properties of electric circuits," IEEE Transactions on Power Delivery, vol. 9, no. 4, pp. 1760-1769, October 1994.
[7] A.E. Emanuel, "Apparent power: components and physical interpretation," in 8th International Conference on Harmonics and Quality of Power, Athens, 1998.

[8] L. S. Czarnecki, "Energy flow and power phenomena in electrical circuits: illusions and reality," Electrical Engineering, vol. 82, no. 3-4, pp. 119-126, March 2000.

[9] Power System Instrumentation and Measurements Committee, IEEE Trial-Use Standard Definitions for the Measurement of Electric Power Quantities Under Sinusoidal, Nonsinusoidal, Balanced, or Unbalanced Conditions, 2000.

[10] IEEE Power Engineering Society, 1459-2010 - IEEE Standard Definitions for the Measurement of Electric Power Quantities Under Sinusoidal, Nonsinusoidal, Balanced, or Unbalanced Conditions, 2010.

[11] Jacques L Willems, "The IEEE standard 1459: What and why?," in 2010 IEEE International Workshop on Applied Measurements for Power Systems, Aachen, 2010. 